\title{
Managing Technical Services in a Changing Environment: The Cornell Experience
}

\section{Christian M. Boissonnas}

\begin{abstract}
Prior to 1993, the technical services sections at Cornell University were traditionally organized. At the request of the university librarian, a library self-study was conducted. Using a structure that included an overall steering committee and 6 functionally oriented task forces, an analysis of technical services was undertaken. In the end, the task forces recommended, and the university librarian accepted, that the traditional structure be replaced by a modular, less hierarchical structure in which staff groups were reorganized around discrete functions. The balance sheet on what was accomplished, naturally, is mixed. Most, but not all, of the changes that were made have had positive results.
\end{abstract}

\section{Technical Services at Cornell}

One of the things that makes life interesting for academic librarians is that there are about as many ways of organizing technical services departments as there are libraries. We are all different and cling to our differences as a matter of pride-if not survival. At Cornell, of course, we organize technical services differently from the rest of you. Part of this is due to the truly bizarre nature of our university. We are, in fact, two institutions: one private, which most people seem to know about, and one quasi-public. The four statutory colleges at Cornell are funded by the State of New York and operate on the state fiscal year. Their staffs are paid on the state scale and receive state benefits. Their students pay state tuition but receive Cornell degrees. So, with the pub- lic/private mix, 4 fiscal years, 8 budgets, the institution is a marvel of complexity and contradictions. Let us now see how this translates into the library picture.

There are 19 libraries at Cornell, 16 on the endowed side, 3 on the state side. Predictably, the technical services picture matches the institution in complexity (see figure 1). Processing activities are concentrated primarily in Central Technical Services and the Catherwood, Law, Mann, and Medical libraries, but some processing takes place in three other libraries. Acquisitions work is done to varying degrees in 7 processing centers, with the heaviest concentration being performed in Central Technical Services.

Cornell has one online catalog for all of its libraries. The decision to have just one catalog was made many years ago and is the major reason we are forced to coordi-

Christian M. Boissonnas (cmb3@cornell.edu) is Director, Central Technical Services, Cornell University Library 107 Olin Library, Ithaca, NY 14853-5301. This article was originally presented at the ALA Annual Conference, July 8, 1996. Manuscript received November 8, 1996; accepted for publication January 30, 1997. 


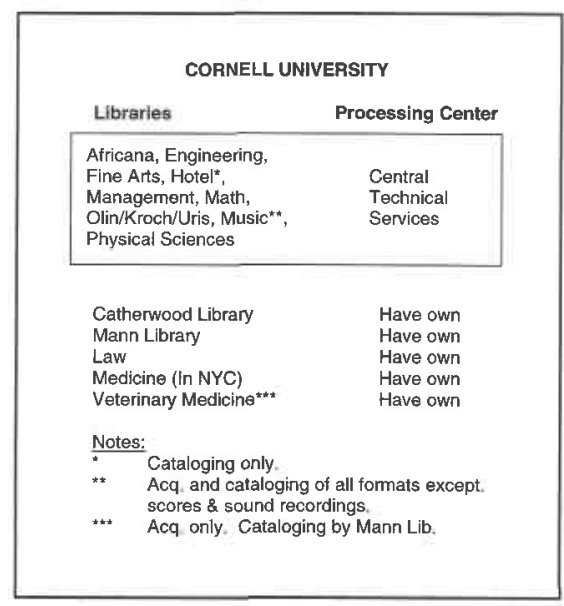

Figure 1. Processing Centers and Libraries Served.

nate activities and policies carefully among all of us. This coordination is managed by one of our two associate university librarians.

Now that I have set the context, let me turn to Central Technical Services, which is the department involved in the changes that concern us here.

\section{Central Technical Services in 1993}

As figure 2 shows, our organization was very traditional. Technical services were divided in three departments: Acquisi- tions, Serials, and Catalog. At various times in our history we have pulled catalog management out and set it up as its own department, but in 1993, it was part of the Catalog Department. The acquisitions functions were split between the Acquisitions and Serials departments. The Acquisitions Department dealt with firm and standing order monograph ordering and receiving, approval, gift and exchanges processing, and pre-order and precataloging searching. The Serials Department was responsible for ordering, claiming and cataloging serials and U.S. federal and state documents. Figure 3 shows the structure of the Acquisitions Department at that time.

The Acquisitions Department was made up of four sections: Orders, Searching, Receiving, and Gifts and Exchanges. At the top of the pyramid sat one assistant university librarian in charge of campuswide technical services. I was then the Acquisitions Librarian. When the assistant university librarian for Technical Services left, I was asked to take over responsibility for the three departments on an acting basis. At the same time I was asked to undertake a self-study of our organizational structure.

\section{The SelF-STUdY}

It was the departure of our assistant university librarian-not budget cutbacksthat caused us to undertake the self-study.

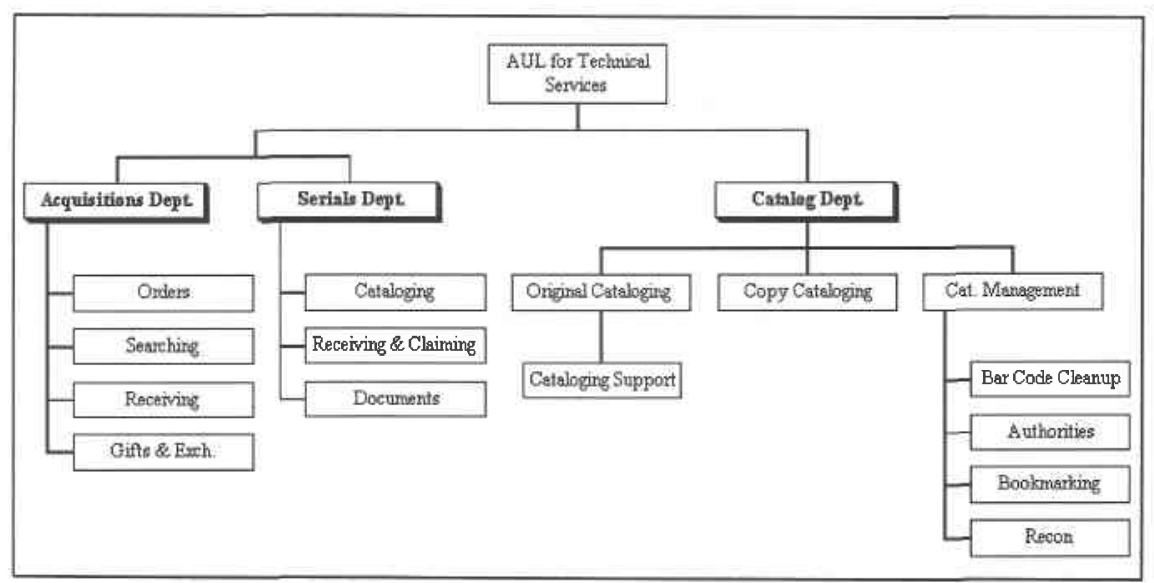

Figure 2. Technical Services Organization, 1993. 


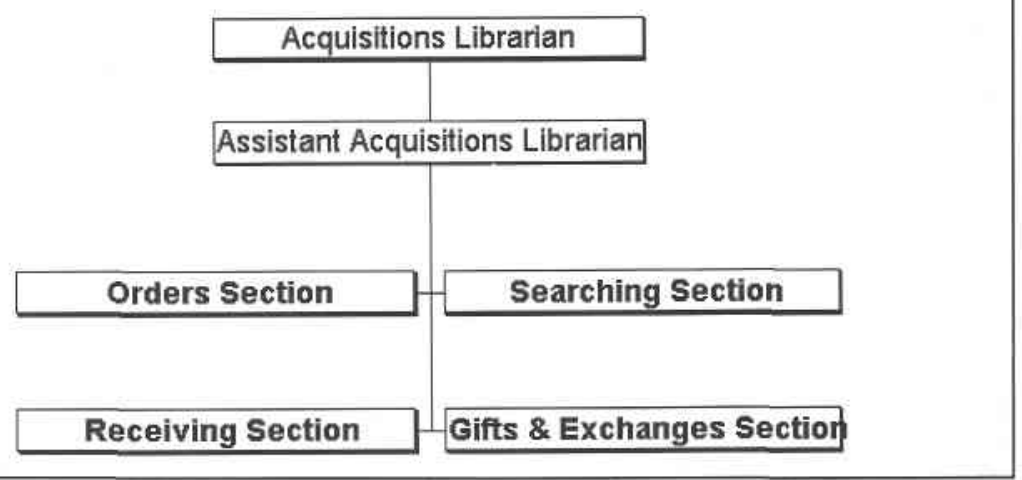

Figure 3. Acquistions Department Organization, 1993.

It had been many years since we had taken a hard look at ourselves, and our university librarian felt that the time had come to do so.

We set up a structure to conduct the self-study, which consisted of a steering committee that included the 3 Central Technical Services department heads and other senior CTS staff (see figure 4 ), and six functional task forces that were charged to review particular functions and make recommendations (see figure 5).

Each task force was composed of the appropriate unit head for the function, the first line supervisors, and some line staff.

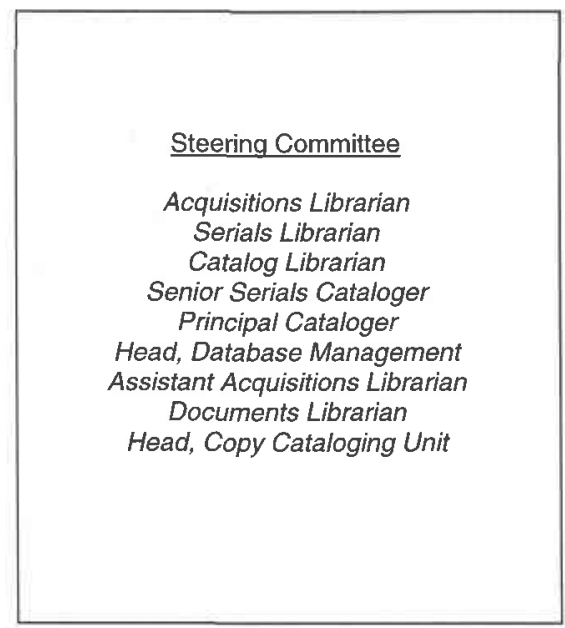

Figure 4. 1993 Self-Study Steering Committee Structure.
The chairs of the task forces, usually the unit heads, were also members of the steering committee. This complex structure was set up to meet two objectives that we knew to be critical in such an effort as we were undertaking: the need to involve as many people as possible, and the need to tap the expertise of staff familiar with the functions being reviewed.

Let us now turn specifically to the acquisitions functions. Figure 6 shows the composition of the two task forces set up to study these functions.

The task forces included staff from both the Serials and Acquisitions Departments. All of the members had extensive experience in the acquisition of all types of library materials. In the early stages of

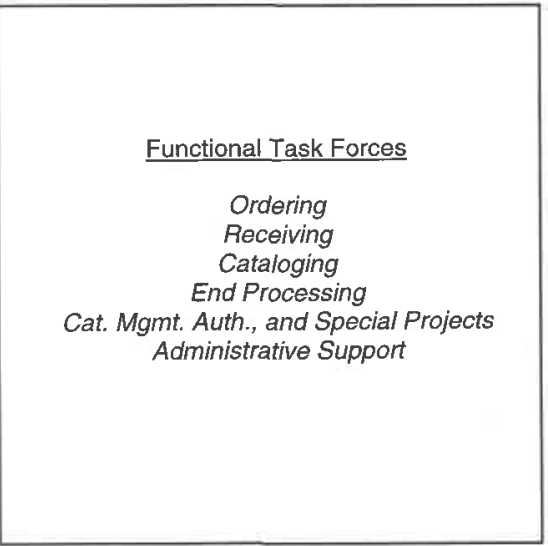

Figure 5. 1993 Self-Study Overall Task Force Structure. 
the review we identified two goals as being paramount:

- To make Central Technical Services more flexible so as to better be able to deploy staff to meet changing user needs, and

- To improve communications across the units.

We believed that our very traditional and hierarchical structure impeded the flow of communications laterally. Further, the lack of shared goals and a common culture contributed to the isolation of each department. While an individual department might have been set up in a way to make it possible to move people around, the departmental barriers prevented such movement across departments.

The task forces met weekly and the steering committee met biweekly. The steering committee's main roles were to assist the task forces as they hit snags and to arrange coordination with other task forces when it was necessary. As things developed, we found out that some task forces were working very fast and others very slowly. Keeping the whole effort synchronized and moving forward became one of the major tasks of the steering committee. The Ordering and Receiving task forces had particularly difficult tasks after it became obvious that one goal should be to merge the acquisitions-related pieces of the Serials Department with the Acquisitions Department, and the cataloging-related pieces with the Catalog Department. There were major cul-

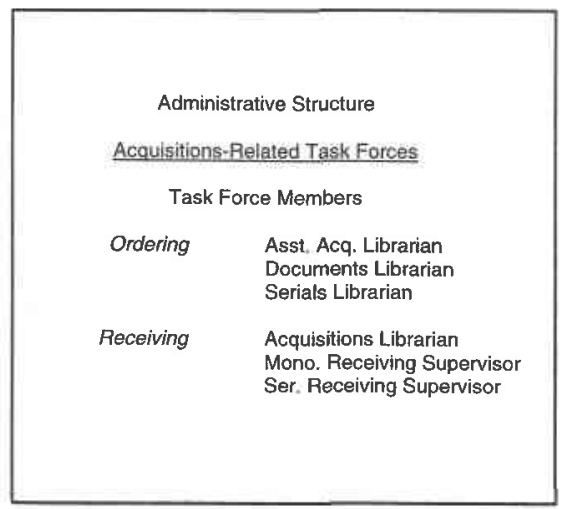

Figure 6. 1993 Self-Study Acquisitions Task Force Structure. tural issues to deal with, adjustments to workflows in all units, and the fear of the loss of identity and jobs of the Serials Department staff, who were witnessing their department disappear from under them.

\section{ACTIONS}

In the end, the task forces recommended, and the University Librarian accepted, that the traditional structure be replaced by a modular, less hierarchical structure in which staff groups were reorganized around discrete functions (see figure 7).

The three departments were replaced by seven smaller administrative units with one, Catalog Management, functioning as a sort of catch-all unit for the functions that were either staffed with very few people or were funded from grants and would disappear in due course. One management layer, that of department head, was almost completely eliminated. One department head retired, one became the Research and Planning Librarian for the system, and the third became head of the new Central Technical Services.

Ordering of all materials, regardless of format, was merged into a new Ordering Section. Receiving of monographs and serials was merged into a new Receiving Section, but at first retained two workflow streams. Supervisors were instructed to begin cross-training their staffs so as to eliminate the two work streams based on format differences as soon as possible. Searching was combined with a process we call "Fastcat," in which very little checking or editing of records is done. Staff in that unit can create bibliographic records, search (both pre-order and precataloging,) or catalog. What they do at any given time depends on the type of work available at that time.

Did we meet our original goals? Absolutely. The new structure forces us to communicate more effectively. The department is too large for one person to manage without delegating a great deal of authority to unit heads. Those unit heads, who are very interdependent, cannot be successful without very frequent communication, something that did not happen in 


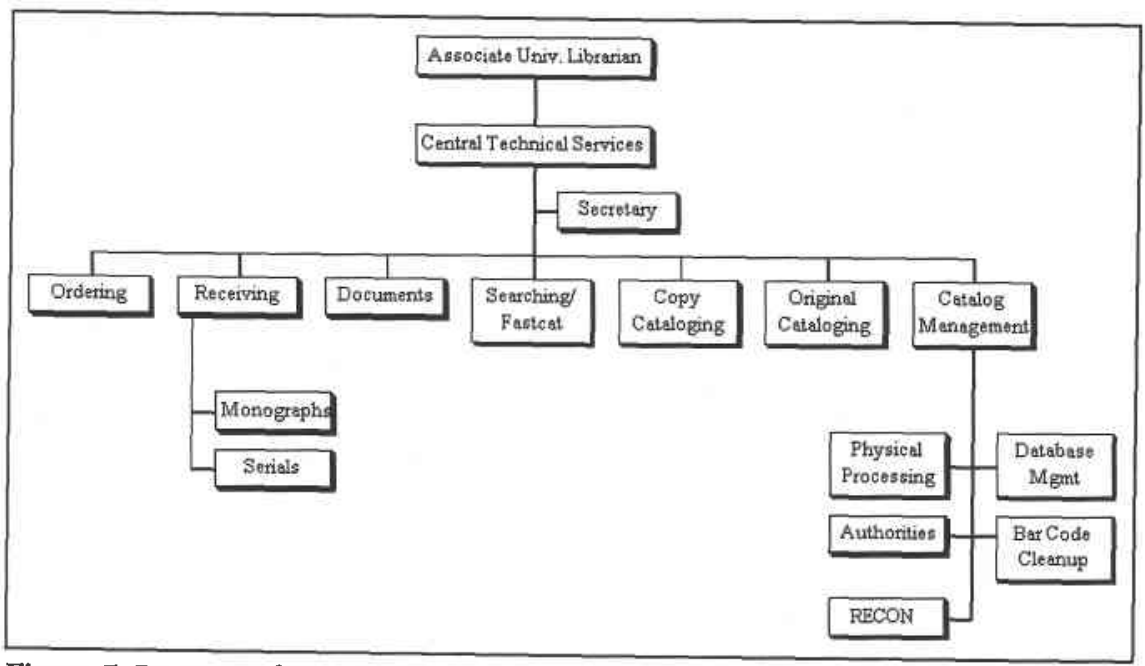

Figure 7. Reorganized Cornell Technical Services.

the earlier configuration of the department. The new structure has also made us much more flexible. In fact, we are now so flexible that we keep changing in response to changing staff, leadership, and conditions. We have reorganized twice since implementing our new structure. The first reorganization took place in March 1995 (see figure 8).

The changes illustrated in figure 8 were made in response to our need to develop a position of Information Technology Librarian. We did this by redesigning the position of Catalog Management and Authorities Librarian. But we also had to find new managers to supervise the functions formerly under the Catalog Management Librarian. We reassigned physical processing to the Acquisitions $\mathrm{Li}$ brarian, authorities to the Head of Original Cataloging, and catalog management to the Documents Librarian. Why this

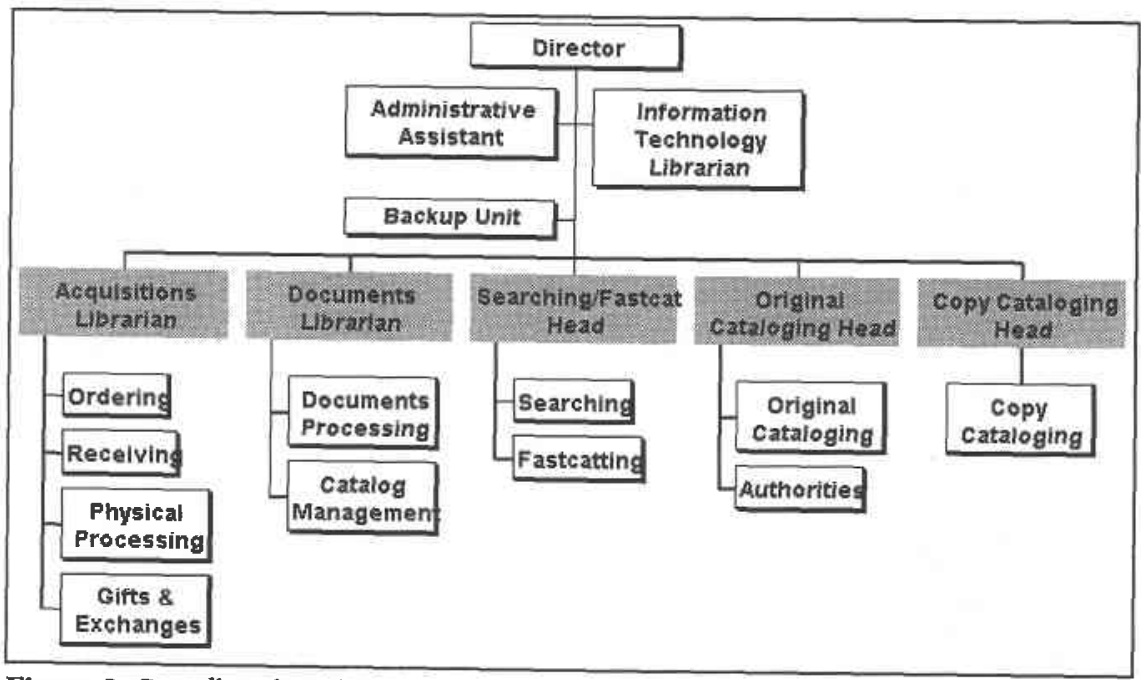

Figure 8. Cornell Technical Services, March 1995. 


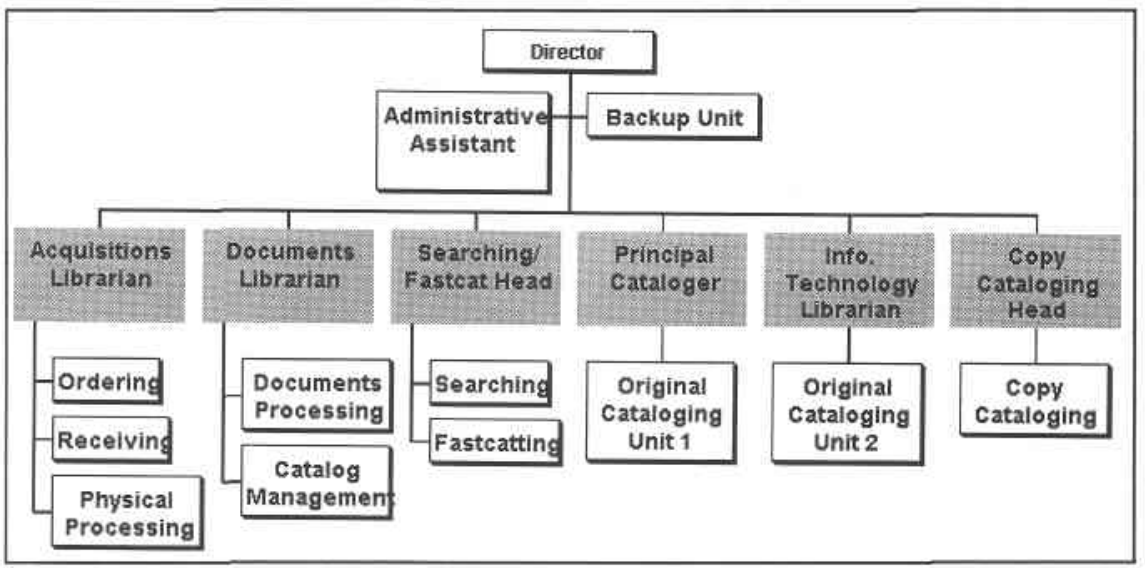

Figure 9. Cornell Technical Services, 1996.

particular lineup? In the case of physical processing, which includes barcoding, we are preparing ourselves to perform these tasks upon receipt of the materials rather than after they are cataloged. We are planning to use the barcode as a tool to control the inventory of in-process materials. Authority work is closely tied to original cataloging; hence the assignment of this function to the Head of Original Cataloging. Catalog management is a particular interest of our Documents Librarian, and she had the fewest number of staff to supervise, so assigning her the responsibility for that function was the logical thing to do.

The second time we reorganized (see figure 9) was upon the departure of the Information Technology Librarian. The changes illustrated were in response to two needs that we had identified earlier but not yet addressed. First, we transferred Gifts and Exchanges to Collection Development. We did this because the decisions that pertain to these functions mostly relate to selection and involve the collection development staff. Once the decision to select or retain a gift or a title received on exchange has been made, there is very little difference in the processing of that title from the processing of all other materials.

The second change that we made was to split the Original Cataloging Section in two. It was too large for the Principal
Cataloger to manage, make cataloging policies, and participate in the overall management of the department as well. This meant having to ask the new Information Technology Librarian to take on some supervisory responsibility. There were no other managers available to take on the responsibility for more staff. Let me now turn specifically to how acquisitions processes have fared.

\section{Acquisitions Then and Now}

The main reason why I have gone through this reorganization in some detail is to demonstrate that the changes in acquisitions cannot be viewed separately from those made elsewhere in our department. Figure 10 summarizes the changes brought to the acquisitions functions by the implementation of the recommendations of our task forces. The most visible change, of course, is that we combined two acquisitions units into one by eliminating a structure based on format differences. We have also reduced the number of acquisitions librarians from two to one, streamlined the acquisitions units by removing functions that fit better elsewhere, and positioned the units for changes that we plan to make in how we physically process books. The verdict on what we accomplished, naturally, is mixed. Most, but not all, of the changes that we made have had positive results. In the rest of this paper I will summarize the positive 
Acquisitions Then and Now

1993

Two librarians

In two departments

Format-dependent

Independent from Cataloging

Includes Gifts \& Exchanges

No Physical Processing
1996

One librarian

In one department

Format-independent

Partner with Cataloging

No Gifts \& Exchange

Includes Physical Processing

Figure 10. Acquisitions-Related Changes Brought About by Reorganizations.

and negative aspects of our reorganization, address the question of what we did to help staff adjust to the changes, and discuss what I would say to others who are about to undergo similar changes.

\section{Positive Aspects}

There were a number of positive aspects observed in our reorganization of processes. First, we achieved better coordination of processes throughout the department. The department's goals are clear to everyone, and so are the adjustments needed on any day to meet the goals. In order of priority these goals are:

1. All orders are to be placed within 72 hours of receipt, $50 \%$ being made within 24 hours, and $75 \%$ in 48 hours.

2. All invoices, except approval invoices, are to be paid within one week of receipt.

3. All new materials must be under bibliographic control within one week of receipt.

4. All new cataloging with copy must be completed within one week of receipt in the cataloging units.

In order to meet these goals, the unit heads must talk, work together, and help each other. They are collectively responsible for the success of the department. The increased communications and elimination of departmental barriers have made us more efficient.
A second positive aspect occurred in the nature of the job tasks that individual staff members performed. Their job tasks became more varied, which they welcome. Third, the acquisitions librarian's job has taken on more professional content.

\section{Negative Aspects}

A number of negative results occurred as well. First, the members of the former Serials Department lost their identity as a work group. Second, although we tried to allocate staff in proportion to the anticipated workloads, we failed to staff the Searching/Fastcat Section satisfactorily. This has resulted in missed deadlines, backlogs, and higher stress for these people. Third, we face the possibility of a real vacuum if the acquisitions librarian leaves, as there is no one to back him up. Fourth, in some staff members we observed uncertainty about how the process was going to work and a fear for their jobs. Finally, there was too much change, too quickly. At the same time that we reorganized administratively, we had to reorganize physically due to circumstances beyond our control. This added to the general confusion.

We took several steps to help staff adjust to the changes. We:

- involved them in planning from the beginning,

- tried to make sure that the supervisors were committed to the changes so that they could help their people, and 
- tried to implement changes incrementally as much as we could.

Others who attempt to undergo similar reorganizational processes might consider the following points:

- Perhaps most important is to make sure that effective communications are taking place continuously while the planning is taking place. We thought we had taken care of that only to find out that the functional task forces initially did not all communicate well with operational staff. Once we understood that this was occurring, we tried to fix it-but it was too late and we never completely recovered lost ground.

- Involve staff from the beginning. Not all of them care, but enough do that their contributions are invaluable.

- Make sure that your goals are clear and that you can explain them. If you cannot, nobody will believe them.

- Do not try to do too much. We were definitely hurt by having to move people physically faster than we wanted to.

- Make sure that your colleagues in other units understand that business cannot be conducted normally while the reorganization is being implemented. Make sure that they understand what your staff will, and will not, be able to do.

- Do not look at acquisitions as a single or separate process. It is not and probably never has been.
- Leave yourself plenty of leeway for things to go wrong. They will.

- If you are the manager, spend 8 hours a day on the floor with your staff on the first two days of the reorganization, then 4 hours on the next two, and 2 hours on the fifth day. Nothing else that you have to do is as important, no matter what you or your boss may think. During that week you should have no other engagements, no other projects. While you are on the floor, work with people who have trouble adjusting. Don't tell them what to do, but help them discover for themselves the solutions to their problems.

\section{Conclusion}

The reorganization that we started in 1993 accomplished its goals. It made us better able to cope with all that we have to do, and it made our managers into a more effective team. It was not accomplished as smoothly as it should have been, primarily because, in spite of our best efforts, we did not sufficiently mind our communication channels and we tried to do too much. It is easy to see now that the major changes we implemented in 1993 were but the opening move in a process that will never end, the process of continuously adjusting to changing conditions. 